\title{
Titanium Dioxide Nanorods as An Effective Blocking Layer in Solar Cells
}

\author{
Natalita M. Nursam ${ }^{\mathrm{a}, 1, \mathrm{~b}, \mathrm{c}, 1}$, Shobih $^{\mathrm{a}, 2}$, J. Pandanga ${ }^{\mathrm{b}, 1}$, Xingdong Wang ${ }^{\mathrm{c}, 2}$ \\ ${ }^{a}$ Research Center for Electronics and Telecommunication, Indonesian Institute of Science (LIPI), Bandung, 40135, Indonesia \\ E-mail: ${ }^{1}$ natalita.maulani.nursam@lipi.go.id, ${ }^{2}$ shob001@lipi.go.id \\ ${ }^{b}$ Department of Physics Engineering, Faculty of Engineering, Surya University, Tangerang 15143, Indonesia \\ E-mail: ${ }^{1}$ pandangajovid@gmail.com \\ ${ }^{c}$ Manufacturing, Commonwealth Scientific and Industrial Research Organization (CSIRO), Clayton VIC, 3168, Australia

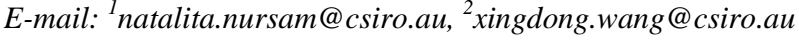

\begin{abstract}
Blocking layer holds a crucial function in dye-sensitized solar cells (DSSC). It essentially prevents recombination from occurring between electrons in the photoanode and the oxidized dye molecules within the electrolyte. Furthermore, this layer could strengthen the connection between the conductive substrate and the photoanode layer. Herein, titanium dioxide $\left(\mathrm{TiO}_{2}\right)$ nanorods were applied as a blocking layer in DSSC, and the solar cell performance was subsequently compared with the cells containing conventional $\mathrm{TiO}_{2}$ nanoparticles blocking layer. $\mathrm{The}^{\mathrm{TiO}_{2}}$ nanorods were grown from titanium isopropoxide (TTIP) solution via the hydrothermal method for various durations, i.e., 30, 60, and $120 \mathrm{~min}$. Meanwhile, the $\mathrm{TiO}_{2}$ nanoparticles blocking layer was deposited via the wet chemistry method by hydrolyzing titanium (IV) chloride $\left(\mathrm{TiCl}_{4}\right)$. The morphology and structure of both types of blocking layers were compared, whereas the electrical properties of the solar cells were analyzed using incident photon-to-current conversion efficiency (IPCE) and current-voltage (I-V) characterization. It was found that different hydrothermal time resulted in $\mathrm{TiO}_{2}$ nanorods with different morphologies. The application of $\mathrm{TiO}_{2}$ nanorods blocking layer that was grown for 120 min led to a photoconversion efficiency of $3.29 \%$, which was $8.2 \%$ and $4.4 \%$ higher than the photoconversion efficiency of cells without the blocking layer and with $\mathrm{TiO}_{2}$ nanoparticles blocking layer, respectively. Our results indicated that the blocking layer with a $\mathrm{TiO}_{2}$ nanorods structure could facilitate better electrons transfer than that of nanoparticles.
\end{abstract}

Keywords - blocking layer; DSSC; hydrothermal, nanorods; $\mathrm{TiO}_{2}$.

\section{INTRODUCTION}

Research on dye-sensitized solar cells (DSSC) has resulted in numerous publications since its first discovery by O'Regan and Graetzel in 1991 [1]. One of the reasons behind the emerging interest in this type of solar cell is because it is a low cost, yet it is highly potential as a new generation commercial solar cells, substituting the siliconbased photovoltaic technology. Despite able to produce over $14 \%$ of photoconversion efficiency [2], many attempts are still required to increase the efficiency of DSSC in order to compete with the performance of silicon-based solar cells. In contrast to the $\mathrm{p}-\mathrm{n}$ junction based solar cells, charge generation and transfer in DSSC occur separately in different materials rather than in a single bulk semiconductor. DSSC is typically constructed using two transparent conducting substrates as electrodes, where one substrate is coated with wide bandgap semiconductor (typically $\mathrm{TiO}_{2}$ ) and dye sensitizer, while the other substrate is coated with catalyst layer. Electrolyte containing redox mediator (typically $\mathrm{I}^{-} / \mathrm{I}_{3}{ }^{-}$) is then filled between the two electrodes to regenerate the charge via reduction-oxidation reaction.

A high-efficiency DSSC typically employs mesoporous $\mathrm{TiO}_{2}$ as a photoanode as it provides high surface area for optimized dye adsorption [3]. However, the sintered $\mathrm{TiO}_{2}$ nanoparticles usually lead to grain boundaries and interfacial contact, which consequently produced surface states near the conduction band of $\mathrm{TiO}_{2}$ [4]. The presence of a high number of surface states is unfavored because it could lower the photoconversion efficiency of DSSC. First, the charge collection could be suppressed due to the trapping and detrapping of electrons from the surface states and the conduction band of $\mathrm{TiO}_{2}$ during the electron transport. Secondly, electrons that occupy the surface states could recombine with either the oxidized dye or the $\mathrm{I}_{3}{ }^{-}$ions within the electrolyte. To prevent the latter phenomenon, a blocking layer could be added as an interfacial layer between the 
transparent conducting oxide (TCO) substrate and the mesoporous $\mathrm{TiO}_{2}$ layer. The addition of a blocking layer could prevent the electrolyte directly in contact with the TCO substrate so that the electrons that already reach TCO can be transferred to the external circuit without suffering from a back reaction to the electrolyte [5]. The blocking layer could also strengthen the connection between TCO substrate and the photoanode layer [6]. Furthermore, a thin layer of a blocking layer with a thickness of less than 100 $\mathrm{nm}$ has been reported to gain a small value of $\mathrm{R}_{\text {series }}$ [7].

A blocking layer is typically composed of dense nanosized $\mathrm{TiO}_{2}$. A common method used to deposit such a blocking layer is carried out by hydrolyzing a titanium salt, namely titanium tetrachloride $\left(\mathrm{TiCl}_{4}\right)$ [8-10]. The deposition is performed via chemical bath deposition in $\mathrm{TiCl}_{4}$ aqueous solution at elevated temperature for at least $30 \mathrm{~min}$. The thin layer of $\mathrm{TiO}_{2}$ produced by this method has been shown to prevent electron-hole recombination and thereby increasing the performance of DSSC [8]. More specifically, $\mathrm{TiO}_{2}$ blocking layer from $\mathrm{TiCl}_{4}$ treatment has been reported to increase the photocurrent activity of DSSC by 30\% [6]. Another precursor material that also can be used to produce a blocking layer is titanium isopropoxide (TTIP) [7]. Overall, the precursor selection usually affects the morphology of the blocking layer particles and, in turn, determines the overall cell performance.

In this research, we propose a novel blocking layer configuration to enhance the performance of DSSC by employing $\mathrm{TiO}_{2}$ nanorods. Photoanodes made from onedimensional nanostructured oxides nanorods, such as $\mathrm{TiO}_{2}$ and $\mathrm{ZnO}$, have been reported to improve the charge collection efficiency in DSSCs [11]-[15]. The various method could be used to obtain such structure, for example, using anodic oxidation, electrochemical etching, or template synthesis, to name a few [16]-[19]. Herein, hydrothermal synthesis was employed to grow vertically aligned $\mathrm{TiO}_{2}$ nanorods due to its versatility. The $\mathrm{TiO}_{2}$ nanorods were employed as a blocking layer and subsequently stacked with mesoporous $\mathrm{TiO}_{2}$ films. To the best of our knowledge, such a proposed structure has never been reported to date since most reports have been made on $\mathrm{TiO}_{2}$ nanorods as a single photoanode layer instead of a blocking layer. The performance of DSSC with the $\mathrm{TiO}_{2}$ blocking layer will be compared with that of widely reported DSSC containing a blocking layer made from the $\mathrm{TiCl}_{4}$ precursor. The effect of the blocking layer deposition method on the physical, optical, and electrical properties of DSSC will be discussed.

\section{MATERIALS AND METHODS}

\section{A. Materials}

De-ionized (DI) water with a resistivity $\sim 5 \mathrm{M} \Omega$ was used throughout the experiment. The following materials were purchased from Great cell Solar, Australia: fluorine-doped tin oxide (FTO) glass with a sheet resistance of $15 \Omega / \mathrm{sq}$, $\mathrm{TiO}_{2}$ nanoparticle paste (DSL 18 NR-AO), platinum paste (PT1), iodide-triiodide based liquid electrolyte (EL-HPE), Ru-based dye Z907, and thermoplastic sealant (Surlyn ${ }^{\mathrm{TM}}$ ). Titanium tetrachloride, titanium isopropoxide (97\%), $\mathrm{TiCl}_{4}$, ethanol (97\% p.a.), and hydrochloric acid (37\%) were purchased from Merck.

\section{B. $\mathrm{TiO}_{2}$ Nanoparticle Blocking Layer}

FTO substrates were initially cut into smaller pieces with a size of $1.5 \times 1 \mathrm{~cm}^{2}$. The FTO glass substrates were cleaned in Teepol ${ }^{\mathrm{TM}}$, deionized (DI) water, and then isopropyl alcohol (IPA) consecutively by ultrasonication for $10 \mathrm{~min}$ for each step. To prepare a reference sample, the cleaned FTO glasses were treated on $40 \mathrm{mmol} \mathrm{L}^{-1} \mathrm{TiCl}_{4}$ solutions at $70{ }^{\circ} \mathrm{C}$ for $30 \mathrm{~min}$, followed by sintering at $450{ }^{\circ} \mathrm{C}$ for $15 \mathrm{~min}$. Another set of the control sample was also prepared without the addition of any blocking layers.

\section{C. $\mathrm{TiO}_{2}$ Nanorods Blocking Layer}

The FTO glass substrates were cleaned following the procedure. $\mathrm{TiO}_{2}$ nanorods were prepared according to methods reported on registered patent P00201910454 [20]. A mixture solution of TTIP with a certain volume was slowly poured into a mixture of $\mathrm{HCl}$ and DI water within a Teflon-lined chamber and then stirred. The Teflon-lined chamber was subsequently placed in a hydrothermal autoclave reactor and heated at $200{ }^{\circ} \mathrm{C}$ for various time. The samples were labeled as $H-x$ min, where $x$ represents the hydrothermal reaction time. Following the hydrothermal process, all samples were rinsed copiously with DI water and then dried naturally in the air.

\section{Solar Cell Fabrication}

The FTO glass that has been pre-coated with a blocking layer was then coated with $\mathrm{TiO}_{2}$ nanoparticle in the form of commercial paste via a screen-printing method, followed by sintering at $500{ }^{\circ} \mathrm{C}$ for 45 minutes. The purpose of this step is to obtain a stacked structure, as illustrated in Fig. 1. Following the screen-printing of the photoanodes, all samples were then immersed in a dye solution that has been dissolved in ethanol and maintained in the dark at room temperature for 24 hours. Once completed, the samples were rinsed in ethanol and then dried in air.

Platinum was used as catalyst material and coated using a screen-printing technique on another FTO substrate, which was designated as a counter electrode. Following the screenprinting, the counter electrodes were annealed at $450{ }^{\circ} \mathrm{C}$ for $30 \mathrm{~min}$. The assembly process was performed according to previous works [21], [22]. The photoanode and counter electrode were constructed in a sandwich-like structure by attaching thermoplastic sealant and pressed at elevated temperature to strengthen the bond between the substrates. Electrolyte (Dyesol, EL-HPE) was subsequently filled into the DSSC cell via injection. Lastly, the remaining gap in the constructed cells was encapsulated with silicone rubber (Dexton).

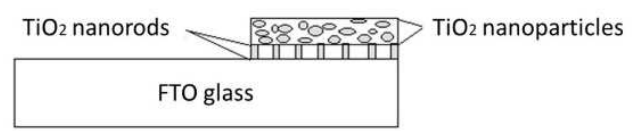

Fig. 1 Schematic illustration of DSSC photoanode comprising $\mathrm{TiO}_{2}$ nanorods as blocking layer.

\section{E. Characterization}

The morphology, structure, and dimension of the $\mathrm{TiO}_{2}$ nanorods were analyzed using scanning electron microscope (SEM) Jeol JSM-IT 300. Crystal phase was characterized 
used XRD on Rigaku, RINT 2200 VK/PC diffractometer, and radiation of copper $\mathrm{K} \alpha(\alpha=1.54056 \AA), 40 \mathrm{kV} 30 \mathrm{~mA}$. The light-harvesting efficiency of DSSC cell was characterized by measuring the external quantum efficiency via incident photon-to-current conversion efficiency (IPCE) measurement technique. The current-voltage (I-V) properties of the solar cells were characterized under Oriel 91192 solar simulator with AM 1.5 filter and measured using the National Instrument I-V measurement system. The photoconversion efficiency, $\eta$, is calculated using the following equation:

$$
\eta=\frac{J_{S C} V_{O C} F F}{P_{\text {in }}} \times 100 \%
$$

where $J_{S C}$ is the short circuit current density $\left(\mathrm{mA} / \mathrm{cm}^{2}\right), V_{O C}$ is the open circuit current $(\mathrm{V}), F F$ is the fill factor, and $P_{\text {in }}$ is the input power (W). The active area of the DSSC cell was $0.25 \mathrm{~cm}^{2}$. For I-V characterization purposes, samples were prepared in triplicates, and the results were presented as the average value.

\section{RESULTS AND DISCUSSION}

\section{A. Structural Properties Analysis}

The formation of $\mathrm{TiO}_{2}$ nanorods structure is known to be affected by the hydrothermal conditions. Thus, a preliminary experiment was conducted to analyze factors that affect the formation of $\mathrm{TiO}_{2}$ nanorods, i.e., precursor concentration and hydrothermal time. Regarding precursor concentration, the TTIP volume was initially varied to see the influence on the nanorods morphology. From our previous results, we discovered that $\mathrm{TiO}_{2}$ nanorods that were synthesized using 2 $\mathrm{mL}$ of TTIP were too dense. When used as a single photoanode layer in DSSC, $\mathrm{TiO}_{2}$ nanorods produced using 2 $\mathrm{mL}$ of TTIP produced lower photoconversion efficiency than the ones produced using $1 \mathrm{~mL}$ of TTIP [23]. Therefore, we used $1 \mathrm{~mL}$ of TTIP to grow the blocking layer for the remaining experiments hereafter.

In addition to precursor concentration, the duration of the hydrothermal reaction is also influential to the growth of $\mathrm{TiO}_{2}$ nanorods. For instance, different hydrothermal reaction time causes different layer thickness formed on the FTO surface [24]. To see the effect of reaction time, the hydrothermal reaction was carried out at $200{ }^{\circ} \mathrm{C}$ for 30,60 and $120 \mathrm{~min}$, whereas the TTIP volume during the hydrothermal reaction was kept at $1 \mathrm{~mL}$. The morphology of the $\mathrm{TiO}_{2}$ nanorods formed under various reaction time is shown in Fig. 2. It can be observed in Fig. 2 that the nanorods morphology appeared when the reaction was carried out for at least $120 \mathrm{~min}$. Fig. 2(a) shows uneven lumps that were formed at the FTO surface during the early stage of hydrothermal reaction, possibly due to the sedimentation of hydrolyzed TTIP material that has not been deposited as nanorods structure [25]. Fig. 2(b) implies that nanofibers started to nucleate after $60 \mathrm{~min}$ of reaction, although the formation was not perfect as suggested by the scarcity of the fibers and the fact that the fibers were mostly still overlapped horizontally to each other. It is also obvious from the visual appearance of the photographs that the FTO was mostly transparent after 30 and $60 \mathrm{~min}$ of reaction, suggesting the absence of $\mathrm{TiO}_{2}$ nanorods. Perfectly formed $\mathrm{TiO}_{2}$ nanorods with a diameter of less than $80 \mathrm{~nm}$ were obtained under the hydrothermal condition for $120 \mathrm{~min}$ (Fig 2(c)). Meanwhile, the SEM images in Fig. 3 highlight the difference between the $\mathrm{TiO}_{2}$ morphologies grown under different synthesis routes. One-dimensional $\mathrm{TiO}_{2}$ nanorods were obtained under hydrothermal synthesis, while hydrolysis of $\mathrm{TiCl}_{4}$ at atmospheric pressure led to the production of $\mathrm{TiO}_{2}$ nanoparticles.

(a)

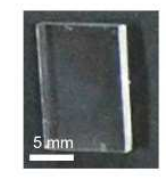

(b)
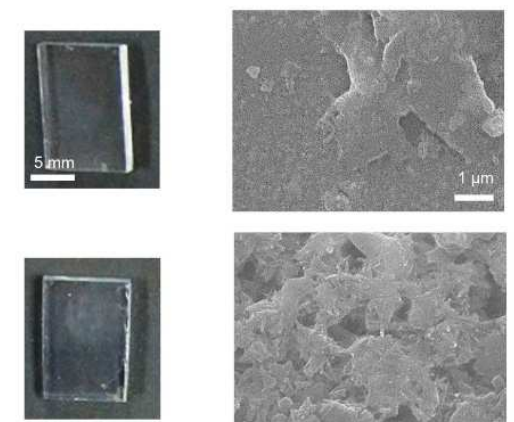

(c)
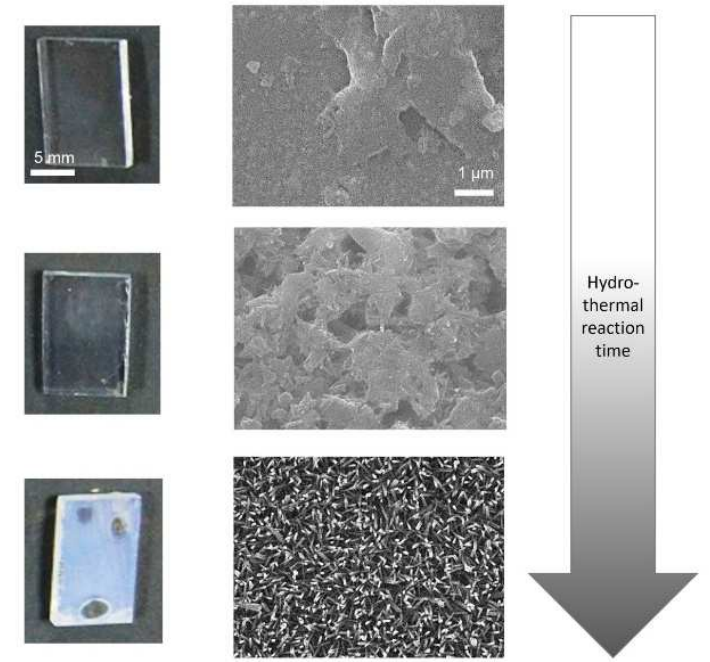

Fig. 2 Photograph and top-view SEM images of $\mathrm{TiO}_{2}$ nanorods blocking layer prepared under hydrothermal reaction at $200{ }^{\circ} \mathrm{C}$ for (a) $30 \mathrm{~min}$, (b) 60 min and (c) $120 \mathrm{~min}$.
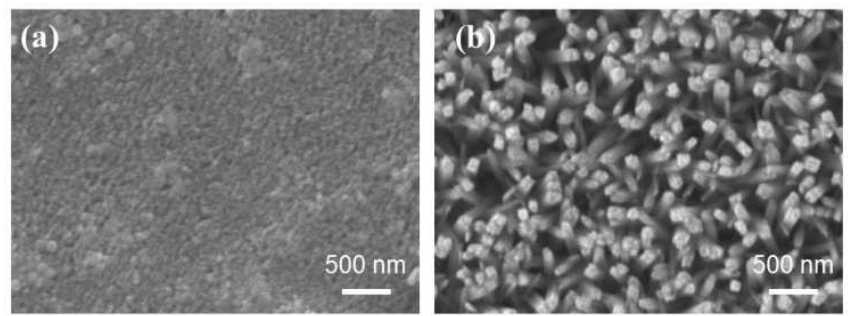

Fig. 3 SEM images of the blocking layer in the form of (a) $\mathrm{TiO}_{2}$ nanoparticles from hydrolyzed $\mathrm{TiCl}_{4}$ and (b) $\mathrm{TiO}_{2}$ nanorods from the hydrothermal reaction at $200{ }^{\circ} \mathrm{C}$ for $120 \mathrm{~min}$.

Fig. 4 shows the X-ray diffraction patterns of $\mathrm{TiO}_{2}$ nanorods arrays grown on top of the FTO substrate at $200{ }^{\circ} \mathrm{C}$ for $120 \mathrm{~min}$. The XRD spectrum was analyzed using an inorganic crystal structure database (ICSD). Herein, two samples containing $\mathrm{TiO}_{2}$ nanoparticles and $\mathrm{TiO}_{2}$ nanorods were compared. The $\mathrm{TiO}_{2}$ nanoparticle sample represents a standard type of $\mathrm{TiO}_{2}$ photoanode without any blocking layers. It should be noted that a direct comparison with $\mathrm{TiO}_{2}$ blocking layer synthesized from hydrolyzed $\mathrm{TiCl}_{4}$ could not be made due to insufficient layer thickness. The XRD spectra from both samples show distinguished peaks that mainly correspond to $\mathrm{TiO}_{2}$ and FTO. The diffraction peaks of FTO could be assigned to the tetragonal phase of $\mathrm{SnO}_{2}$. The $\mathrm{TiO}_{2}$ nanoparticles only show anatase peaks as indicated by the sharp diffraction at $2 \theta \sim 25^{\circ}$ that corresponds to (101) crystal planes (JCPDS 21-1272). Meanwhile, the diffraction pattern of the sample containing $\mathrm{TiO}_{2}$ nanorods indicates a mixture of both anatase and rutile phase (JCPDS 21-1276). Anatase phase is typically preferred as a photoanode in DSSC due to a higher surface area [26]. However, since the $\mathrm{TiO}_{2}$ nanorods were employed solely as a blocking layer, the rutile phase may become favorable to improve the 
photovoltaic cell performance as it could accelerate the charge transfer rate from the photoanode towards the FTO [14].

The transmittance spectra of FTO substrates with various blocking layers and without any coating (i.e., bare FTO) are shown in Fig. 5(a). The transmittance spectroscopy of the substrate coated with a blocking layer derived from hydrolyzed $\mathrm{TiCl}_{4}$ slightly resembles that of FTO, particularly within the visible range, because the sample itself appeared mostly transparent. Lower transmittance level below $500 \mathrm{~nm}$ for all samples with a blocking layer was attributed to the $\mathrm{TiO}_{2}$ absorption as $\mathrm{TiO}_{2}$ is known to absorb ultraviolet (UV) light. Precisely, the absorption peak at $\sim 370 \mathrm{~nm}$ corresponds to the optimum absorption of $\mathrm{TiO}_{2}$ as it coincides with the characteristic bandgap energy of $\mathrm{TiO}_{2}$. The increase in the UV light absorbance with the increase in hydrothermal reaction time is clearly visible for samples with $\mathrm{TiO}_{2}$ nanorods blocking layer. This phenomenon was attributed to the increase in blocking layer thickness, as indicated by the decrease in sample transparency. Longer hydrothermal reaction time led to a thicker blocking layer, thereby lowering the light transmission. In order to estimate the energy gap characteristic, the diffused reflectance of $\mathrm{TiO}_{2}$ nanorods blocking layer was measured, and the absorbance was then calculated using Kubelka-Munk formula. The bandgap energy was determined using the following modified Kubelka-Munk $(F(R))$ equation [27]:

$$
F(R)=\left[\frac{(1-R)^{2}}{2 R}\right]^{1 / n}
$$

where $R$ is the diffused reflectance, and $n$ was determined by the type of semiconductor. Herein, $n$ value of 2 was used as $\mathrm{TiO}_{2}$ is an indirect bandgap semiconductor. Fig. 5(b) shows the modified Kubelka-Munk $(F(R))$ equation plotted versus the energy of light $(h v)$. The bandgap energy, $E_{g}$, of approximately $3.28 \mathrm{eV}$ was determined from the intercept of the $\mathrm{x}$-axis and the tangential line of $F(R)$ as represented by the dashed line. This value indicated that the optical properties of $\mathrm{TiO}_{2}$ nanorods blocking layer is like the typical characteristics of $\mathrm{TiO}_{2}$ nanoparticles.

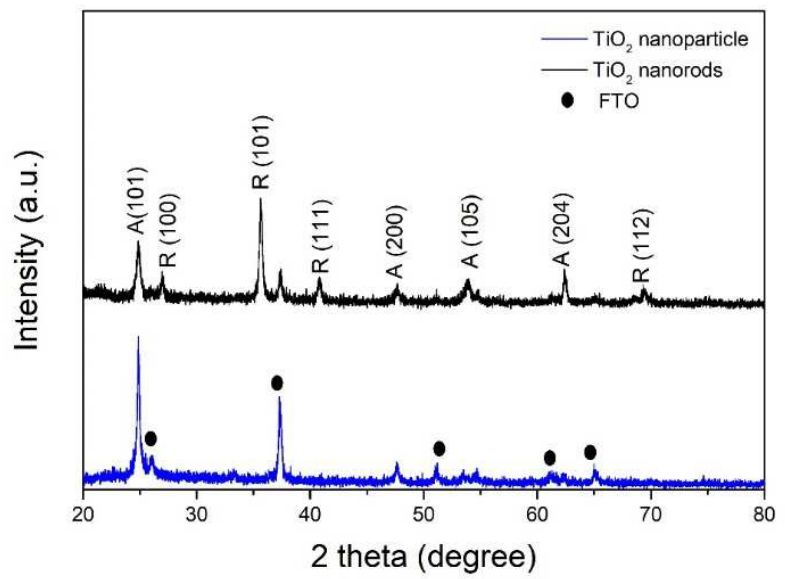

Fig. 4 XRD patterns of $\mathrm{TiO}_{2}$ nanoparticles and nanorods were grown and measured on top of FTO glass substrates. The A and R symbol represent anatase and rutile peak, respectively. The diffraction pattern of $\mathrm{TiO}_{2}$ nanorods was offset along the $y$-axis for clarity purposes.

\section{B. Electrical Properties Analysis}

Fig. 6(a) shows the comparison of the current-voltage (IV) characteristics generated by DSSC with the various blocking layer. The output parameters of the solar cells, such as short circuit current density $\left(J_{S C}\right)$, open circuit current $\left(V_{O C}\right)$, maximum power $\left(P_{\max }\right)$, fill factor $(F F)$, parasitic resistances $\left(R_{s}\right.$ and $\left.R_{s h}\right)$, and efficiency were shown in Table 1. The addition of blocking layer could improve the overall performance of DSSC, resulting in higher photoconversion efficiency (PCE). The highest performance was shown by the DSSC sample containing $\mathrm{TiO}_{2}$ nanorods blocking layer with $J_{S C}$ of $0.99 \mathrm{~mA} / \mathrm{cm}^{2}, V_{O C}$ of $0.69 \mathrm{~V}, P_{\max }$ of $0.41 \mathrm{~mW}$, $F F$ of 0.62 , and PCE of $3.29 \%$. As a result, the PCE of the cells with $\mathrm{TiO}_{2}$ nanorods blocking layer was in approximately $8.2 \%$ and $4.4 \%$ higher than the PCE of the cells without and with $\mathrm{TiCl}_{4}$ blocking layer, respectively. Although the PCE was only marginally improved, it can be discerned that the distinct enhancement was contributed by the $J_{S C}$. This is also confirmed from the IPCE result shown in Fig. 5(b).

a)

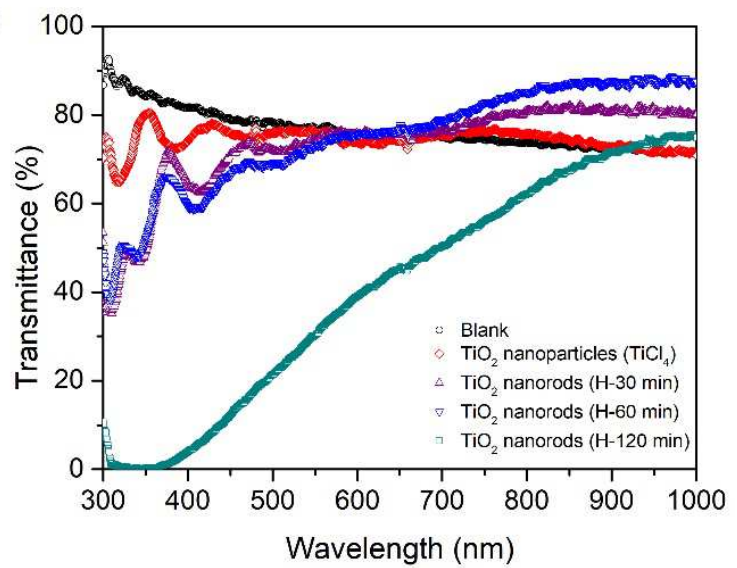

b)

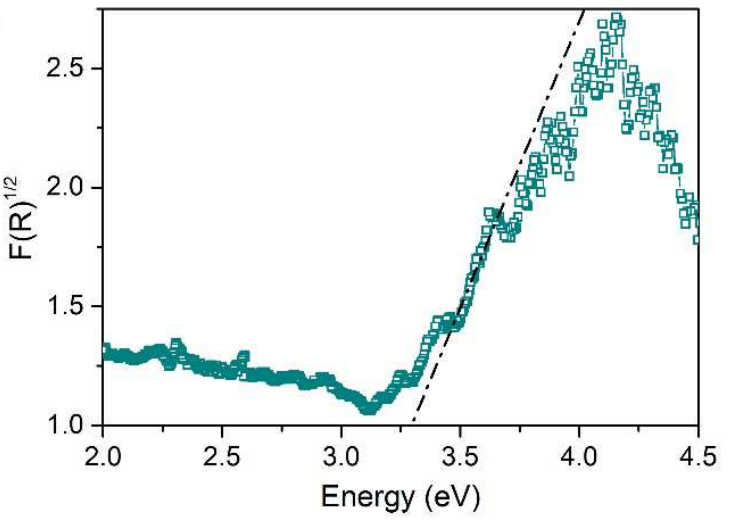

Fig. 5 UV-Vis (a) transmittance and (b) modified Kubelka-Munk from the diffused reflectance of $\mathrm{TiO}_{2}$ nanorods grown via hydrothermal reaction for $120 \mathrm{~min}$.

TABLE I

PHOtOVOlTAIC CHARACTERISTICS OF DSSC WITH VARIOUS BLOCKING LAYER

\begin{tabular}{|l|l|l|l|l|l|}
\hline $\begin{array}{c}\text { Type of blocking } \\
\text { layer }\end{array}$ & $\begin{array}{c}P_{\max } \\
(\mathrm{mW})\end{array}$ & $\begin{array}{c}J_{S C} \\
(\mathrm{~mA} / \\
\left.\mathrm{cm}^{2}\right)\end{array}$ & $\begin{array}{c}V_{O C} \\
(\mathrm{volt})\end{array}$ & $F F$ & $\begin{array}{c}\eta \\
(\%)\end{array}$ \\
\hline- & 0.38 & 3.77 & 0.69 & 0.59 & 3.04 \\
\hline $\mathrm{TiO}_{2}$ nanoparticle & 0.40 & 4.32 & 0.69 & 0.52 & 3.15 \\
\hline $\mathrm{TiO}_{2}$ nanorods & 0.41 & 4.73 & 0.69 & 0.62 & 3.29 \\
\hline
\end{tabular}


The external quantum efficiency (EQE) represents the ability of photons in certain wavelength ranges to excite electrons to become electrical energy. Fig. 6(b) provides the EQE spectra of DSSC with various blocking layer, showing peak efficiency between 500-550 nm that could be attributed to the absorption peak of Z-907 dye.
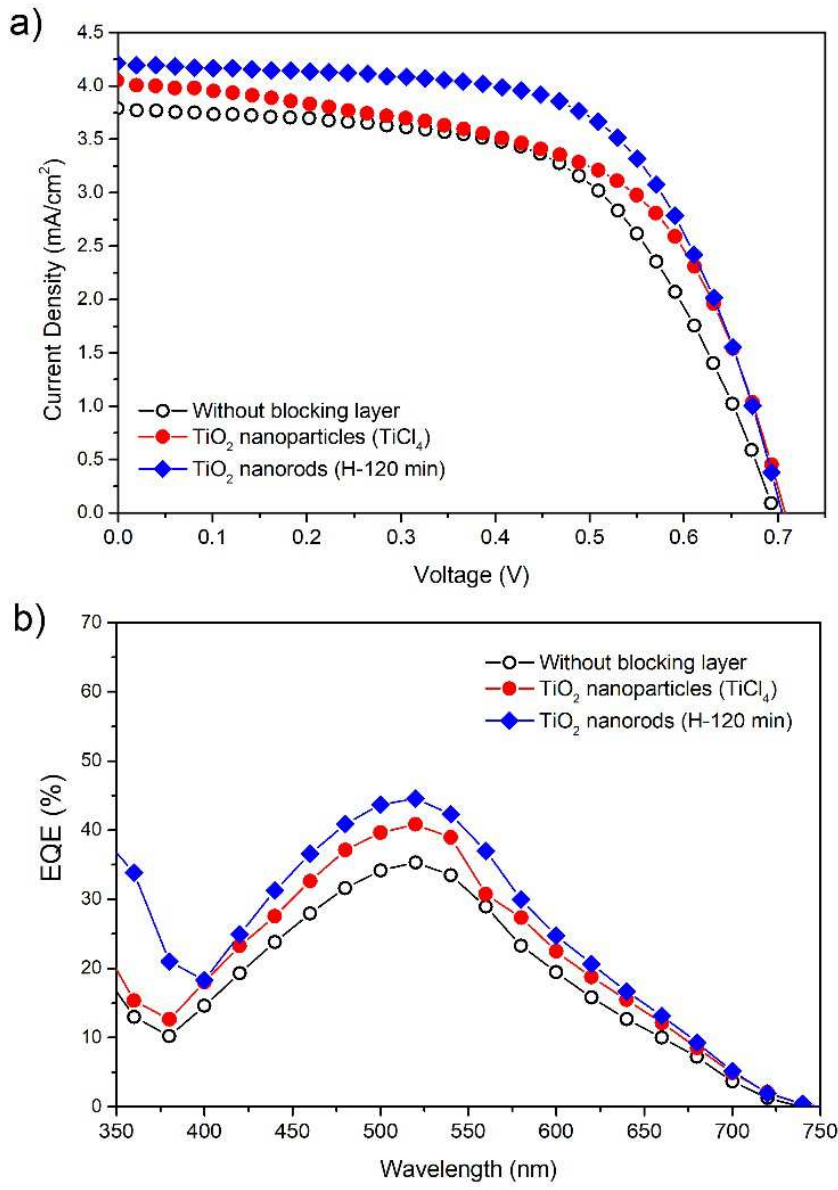

Fig. 6 (a) I-V characteristics and (b) IPCE spectra of DSSC without and with blocking layer in the form of $\mathrm{TiO}_{2}$ nanoparticles (from hydrolyzed $\mathrm{TiCl}_{4}$ ) and $\mathrm{TiO}_{2}$ nanorods (from hydrothermal for $12 \mathrm{~min}$ ).

Overall, the presence of the blocking layer enhanced the photon-to-current conversion efficiency in DSSC, as indicated by the higher broader IPCE spectra. Fig. 6(b) also shows that the highest quantum efficiency was achieved by the DSSC sample with the $\mathrm{TiO}_{2}$ nanorods blocking layer. This trend agrees with the current-voltage measurement results, wherein the sample with the $\mathrm{TiO}_{2}$ nanorods blocking layer produced the highest $J_{s c}$. Since all samples had the same photoanode layer and thus presumably have similar dye adsorption, the higher $J_{s c}$ and EQE suggest that the presence of the blocking layer had a significant influence on the charge collection. It is likely that higher photoconversion efficiency and EQE of DSSC with the blocking layer were attributed by the reduced recombination rate [28], [29]. As illustrated in Fig. 7, electrons transport from $\mathrm{TiO}_{2}$ towards FTO occurred faster due to shorter transfer path when $\mathrm{TiO}_{2}$ nanorods were applied as a blocking layer, thereby further preventing charge recombination, and increasing the charge collection. Despite having compromised optical transmission (see Fig. 5(a)), the effect of fast charge transport by the $\mathrm{TiO}_{2}$ nanorods blocking layer was therefore presumed to be significant enough to compensate for the loss of light absorption toward the photoanode. It is believed that higher photoconversion efficiency could be achieved by adjusting the transparency of the $\mathrm{TiO}_{2}$ nanorods layer via further morphological modification.

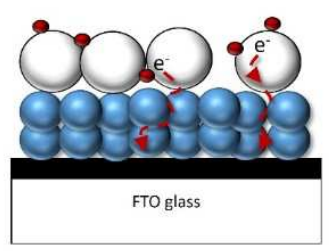

(a)

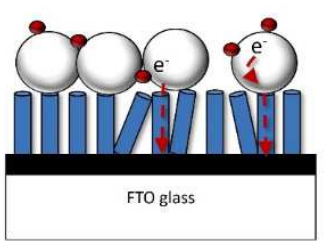

(b)
Fig. 7 Schematic illustration comparing the proposed mechanism of electron injection via (a) $\mathrm{TiO}_{2}$ nanoparticles blocking layer and (b) $\mathrm{TiO}_{2}$ nanorods blocking layer.

\section{CONCLUSIONS}

The blocking layer in the form of the $\mathrm{TiO}_{2}$ nanorods structure was grown directly on top of the FTO conductive substrate using a hydrothermal technique and applied in DSSC. The effect of $\mathrm{TiO}_{2}$ nanorods blocking layer on the cell performance was systematically compared with the cells featuring the $\mathrm{TiO}_{2}$ nanoparticles blocking layer. $\mathrm{TiO}_{2}$ nanorods produced a thicker blocking layer than $\mathrm{TiO}_{2}$ nanoparticles and thus resulting in lower optical transmission property. Nevertheless, the DSSC with $\mathrm{TiO}_{2}$ nanorods blocking layer prepared using hydrothermal synthesis for $120 \mathrm{~min}$ generated $3.29 \%$ of efficiency, higher than that of the $\mathrm{TiO}_{2}$ nanoparticles blocking layer that produced $3.15 \%$ of efficiency. The improvement was attributed to the enhanced charge transfer by the $\mathrm{TiO}_{2}$ nanorods. The application of $\mathrm{TiO}_{2}$ nanorods has been shown to be highly viable as a blocking layer in improving the photoconversion efficiency and external quantum efficiency of DSSC.

\section{ACKNOWLEDGMENT}

The authors acknowledge the support of the Materials and Devices for Solar Cells research group at the Research Center for Electronics and Telecommunication, Indonesia Institute of Sciences (P2ET LIPI). NMN is the main contributor that led the project, designed the research, and wrote the paper. S collected the data, XW performed data analysis, and JP fabricated the samples. Research Unit for Clean Technology (LPTB) LIPI and CSIRO Manufacturing is acknowledged for the SEM access. Research Center for Physics (P2F) LIPI is acknowledged for conducting the XRD measurement. The DIPA LIPI research grant supported this work. NMN thanks the 2019 Australia-APEC Women in Research fellowship for the research and travel fund to Australia.

\section{REFERENCES}

[1] B. O'Regan and M. Gratzel, "A low-cost, high-efficiency solar cell based on dye-sensitized colloidal $\mathrm{TiO}_{2}$ films," Nature, vol. 353, pp. 737-740, 1991. 
[2] K. Kakiage, Y. Aoyama, T. Yano, K. Oya, J.-i. Fujisawa, and M. Hanaya, "Highly-efficient dye-sensitized solar cells with collaborative sensitization by silyl-anchor and carboxy-anchor dyes," Chem. Commun., vol. 51, no. 88, pp. 15894-15897, 2015.

[3] J. M. Kroon, N. J. Bakker, H. J. P. Smit, P. Liska, K. R. Thampi, P. Wang, S. M. Zakeeruddin, M. Grätzel, A. Hinsch, S. Hore, U. Würfel, R. Sastrawan, J. R. Durrant, E. Palomares, H. Pettersson, T. Gruszecki, J. Walter, K. Skupien, and G. E. Tulloch, "Nanocrystalline dye-sensitized solar cells having maximum performance," Prog. Photovoltaics Res. Appl., vol. 15, no. 1, pp. 1-18, 2007.

[4] P. J. Cameron and L. M. Peter, "Characterization of titanium dioxide blocking layers in dye-sensitized nanocrystalline solar cells," J. Phys. Chem. B, vol. 107, no. 51, pp. 14394-14400, 2003.

[5] A. Sangiorgi, R. Bendoni, N. Sangiorgi, A. Sanson, and B. Ballarin, "Optimized $\mathrm{TiO}_{2}$ blocking layer for dye-sensitized solar cells," Ceram. Int., vol. 40, no. 7, Part B, pp. 10727-10735, 2014

[6] M. Shakeel Ahmad, A. K. Pandey, and N. Abd Rahim, "Advancements in the development of $\mathrm{TiO}_{2}$ photoanodes and its fabrication methods for dye sensitized solar cell (DSSC) applications. A review," Renewable Sustainable Energy Rev., vol. 77, pp. 89-108, 2017.

[7] D. Jianping, L. Jing, W. Minqiang, and S. Xiaohui, "The influence of blocking layer on the photovoltaic performance of organometal halide perovskite solar cell," in Proc. 14th IEEE International Conference on Nanotechnology, 2014, pp. 789-793.

[8] H. K. Adli, T. Harada, S. Nakanishi, and S. Ikeda, "Effects of $\mathrm{TiCl}_{4}$ treatment on the structural and electrochemical properties of porous $\mathrm{TiO}_{2}$ layer in $\mathrm{CH}_{3} \mathrm{NH}_{3} \mathrm{PbI}_{3}$ perovskite solar cells," Phys. Chem. Chem. Phys., vol. 19, pp. 26898-26905, 2017.

[9] Y. Xu, C. Gao, S. Tang, J. Zhang, Y. Chen, Y. Zhu, and Z. Hu, "Comphrehensive understanding of $\mathrm{TiCl}_{4}$ treatment on the compact $\mathrm{TiO}_{2}$ layer in planar perovskite solar cells with efficiencies over 20\%," J. Alloys Comp., vol. 787, pp. 1082-1088, 2019.

[10] V. Ostapchenko, Q. Huang, Q. Zhang, and C. Zhao, "Effect of $\mathrm{TiCl}_{4}$ treatment on different $\mathrm{TiO}_{2}$ blocking layer deposition methods" Int. J. Electrochem. Sci., vol. 12, pp. 2262-2271, 2017.

[11] Z. Jin, S. Chen, Y. Zhang, Y. Wang, X. Zhang, and Y. Liu, "Construction of hierarchical hetero-structured $\mathrm{TiO}_{2}$ photoanodes for dye-sensitized solar energy conversion: Case study of anatase nanobranches on rutile nanorod arrays," Chem. Phys., vol. 522, pp. 129-133, 2019.

[12] K. Li, Q. Sun, S. Wu, D. You, T. Zang, L. Yu, L. Sui, and L. Dong, "The remarkable morphology regulatory effect of $\mathrm{NH}_{4}{ }^{+}$ions on $\mathrm{TiO}_{2}$ nanorod arrays and their application in dye-sensitized solar cells," Appl. Phys. A, journal article vol. 125, no. 4, p. 245, 2019.

[13] K. P. Ghoderao, S. N. Jamble, and R. B. Kale, "Influence of reaction temperature on hydrothermally grown $\mathrm{TiO}_{2}$ nanorods and their performance in dye-sensitized solar cells," Superlattices Microstruct., vol. 124, pp. 121-130, 2018

[14] X. Feng, K. Zhu, A. J. Frank, C. A. Grimes, and T. E. Mallouk, "Rapid charge transport in dye-sensitized solar cells made from vertically aligned single-crystal rutile $\mathrm{TiO}_{2}$ nanowires," Angew. Chem. Int. Ed., vol. 51, no. 11, pp. 2727-2730, 2012.

[15] J. E. M. Haverkort, E. C. Garnett, and E. P. A. M. Bakkers, "Fundamentals of the nanowire solar cell: Optimization of the open circuit voltage," Appl. Phys. Rev., vol. 5, no. 3, p. 031106, 2018.

[16] L. Meng, H. Chen, C. Li, and M. P. dos Santos, "Growth of the [110] oriented $\mathrm{TiO}_{2}$ nanorods on ITO substrates by sputtering technique for dye-sensitized solar cells," Front. Mater., vol. 1, no. 14, 2014.

[17] D. Gong, C. A. Grimes, O. K. Varghese, W. Hu, R. S. Singh, Z. Chen, and E. C. Dickey, "Titanium oxide nanotube arrays prepared by anodic oxidation," J. Mater. Res., vol. 16, no. 12, pp. 3331-3334, 2011.

[18] J.-h. Hu, W.-h. Liu, Y.-p. Yang, L. Zhao, Y. Qiao, S.-h. Li, P.-h. Liu, and M.-w. Chen, "TiO ${ }_{2}$ nanotube/ $\mathrm{TiO}_{2}$ nanoparticle hybrid photoanode for hole-conductor-free perovskite solar cells based on carbon counter electrodes," Optical Materials Express, vol. 7, no. 9 , pp. 3322-3331, 2017.

[19] Y. K. Kwok, "Methodologies for achieving 1D ZnO nanostructures potential for solar cells," in Renewable and Sustainable Composites, A. Pereira and F. A. O. Fernandes, Eds.: Intechopen, 2019

[20] N. M. Nursam, Shobih, E. S. Rosa, J. Hidayat, P. N. Anggraini, L. Muliani, and L. Retnaningsih, "Fotoanoda berlapis $\mathrm{TiO}_{2}$ nanorods dan $\mathrm{TiO}_{2}$ mesopori beserta metode pembuatannya," Registered patent P00201910454, Indonesia, 2019.

[21] N. M. Nursam, J. Hidayat, Shobih, E. S. Rosa, and L. M. Pranoto, "A comparative study between titania and zirconia as material for scattering layer in dye-sensitized solar cells," J. Phys.: Conf. Ser., vol. 1011, p. 012003, 2018.

[22] N. M. Nursam, L. M. Pranoto, and J. Hidayat, "Application of large area $\mathrm{TiO}_{2}$ photoelectrode on dye-sensitized solar cells," Jurnal Elektronika dan Telekomunikasi, vol. 12, pp. 70-76, 2012.

[23] J. J. Pandanga, N. M. Nursam, Shobih, and N. Prastomo, "Synthesis and application of $\mathrm{TiO}_{2}$ nanorods as photo-anode in dye-sensitized solar cells," J. Phys.: Conf. Ser., vol. 1191, p. 012023, 2019.

[24] B. Liu and E. S. Aydil, "Growth of oriented single-crystalline rutile $\mathrm{TiO}_{2}$ nanorods on transparent conducting substrates for dyesensitized solar cells," J. Am. Chem. Soc., vol. 131, no. 11, pp. 39853990, 2009.

[25] W. Peng, M. Yanagida, L. Han, and S. Ahmed, "Controlled fabrication of $\mathrm{TiO}_{2}$ rutile nanorod/anatase nanoparticle composite photoanodes for dye-sensitized solar cell application," Nanotechnology, vol. 22, no. 27, p. 275709, 2011.

[26] N. G. Park, J. van de Lagemaat, and A. J. Frank, "Comparison of dye-sensitized rutile- and anatase-based $\mathrm{TiO}_{2}$ solar cells," J. Phys. Chem. B, vol. 104, no. 38, pp. 8989-8994, 2000.

[27] J. Tauc, Grigorov.R, and A. Vancu, "Optical properties and electronic structure of amorphous germanium," (in English), Phys. Status Solidi, vol. 15, no. 2, pp. 627-637, 1966.

[28] G. Boschloo, "Improving the efficiency of dye-sensitized solar cells," Frontiers in Chem., vol. 7, no. 77, 2019.

[29] S. I. Cho, H. K. Sung, S. Lee, W. H. Kim, D. Kim, and Y. S. Han, "Photovoltaic performance of dye-sensitized solar cells containing ZnO microrods," Nanomater., vol. 9, no.1645, 2019. 